\title{
AGENT BASED MODEL OF THE E-MINI FUTURE: APPLICATION FOR POLICY MAKING
}

\author{
Roy Hayes \\ Mark Paddrik \\ Andrew Todd \\ Steve Yang \\ Peter Beling \\ William Scherer \\ University of Virginia \\ Charlottesville, VA 22904, USA
}

\begin{abstract}
An agent-based model (ABM) has a structure, which includes a set of agents, a topology and an environment. A simplified conception of a financial market includes a set of market participants, a trading mechanism, and a set of securities. In a typical ABM of a financial market, the market participants are agents, the market mechanism is the topology and the exogenous flow of information into the market is the environment. A zero-intelligence ABM model of the E-Mini Futures Market is presented. Several classes of agents are characterized by their speed and placement of orders within the limit order book. The proposed minimum quote life rule is implemented in the simulation. The minimum quote life rule prevents new orders from being cancelled or modified before a given time limit. Through experimentation, tradeoff curves are generated. Thereby, illustrating the usefulness of this ABM and its ability to inform ongoing financial policy debates.
\end{abstract}

\section{INTRODUCTION}

The Commodity and Future Trade Commission (CFTC) is mandated to ensure fair and orderly markets. Since the inception of CFTC in 1974, markets have evolved and so has the definition of fair and orderly. The Dodd-Frank Act, passed July 2010, imposed new rules and regulations on the Financial Industry (Dodd 2010). One of the goals of the act is to update regulations to better reflect the new financial environment. However, since the rule making process redefines fair behavior in the market, a detailed analysis of the cost and benefits of each rule must be examined.

In July 2011, a federal judge struck down a Dodd-Frank rule imposed by the Security and Exchange Commission, sighting the Cost Benefit analysis was inadequate (Holzer 2011). An in depth cost benefit analysis is challenging to accomplish in today's financial markets. Financial markets are made up of agents operating independently, towards their own personal goals. The interactions of these agents create what is known as an emergent property. An emergent property is a phenomenon that arises from independent actors' interactions with each other and cannot be estimated from a single individual's or subset of individuals' actions. Emergent properties requires all actors' interactions to reproduce in its entirety; the price movement of a stock is an example of an emergent property (Maslov 2000).

An ecosystem is a good analogy of a financial market. Animals live and act independently of one another. However, their interactions with each other and the environment creates a stable ecosystem. A rule change is analogous to changing the aforementioned interactions. It is hard to predict what effect changing the interactions between two animals will have on the food chain or ecosystem as a whole. 
Agent based modeling was developed to help understand complex interactions. A simplified conception of a financial market includes a set of market participants, a trading mechanism, and a set of securities. An agent-based model (ABM) has a similar structure and includes a set of agents, a topology and an environment (Macal 2010). In a typical ABM of a financial market, the market participants are agents, the market mechanism is the topology and the exogenous flow of information, relevant to the market, is the environment. The simulation is a zero-intelligence ABM of the limit order book, where agents' actions are drawn from underlying random distributions.

It is important to note that Agent Based Models do not accurately predict expected values of statistics, such as volatility. However, they can define the shape of a tradeoff curve as parameters of a rule are varied. Agent based models illustrate how the rule may affect different traders. This can help policies maker create targeted regulations that have minimal side effects on the financial market. Additionally, it can help policy makers justify their regulations to the public.

The next section will give a review of previous agent based financial models and the formal rule making process. Section 3 will detail how the model is designed. The Validation process of the model is described in the paper Agent Base Model of the E-Mini: For Flash Crash Analysis (Paddrik et al. 2012).

High frequency traders have recently been a focus of regulatory bodies. Some academics and practitioners take the position that HFTs increase volatility (Zhang 2010). However, others believe that they increase liquidity by decreasing the spread and time between trades (Brogaard 2010). In section 3 a regulation that imposes a minimum quote life before a new order can be modified or cancel is examined and the tradeoffs between volatility, spread, market depth, time between trades and liquidity ratio are presented. Section 4 provides a cost benefit analysis and Section 5 concludes with future work.

\section{LITERATURE REVIEW}

\subsection{Agent Based Model Literature Review}

Maslov (2000) proposed one of the first zero-intelligence financial agent based model of a limit order book market. The goal was to reproduce non-Gausian price returns, a non-trivial Hurst exponent and volatility clustering. Agents in zero-intelligence models draw their actions from underlying random distributions. These actions may be constrained by a set of rules, such as position limits.

Maslov's (2000) model introduces a new trader at each time step that is either a buyer or a seller with equal probability. The trader places a limit order with probability $q$ and trades at the market price with probability $(1-q)$. The price of the limit order is uniformly randomly offset from the last traded price, which is seen as a reasonable first-order approximation of participant behavior. Orders are not canceled or modified and remain until executed. The model produced a price time-series exhibiting characteristics in loose agreement with empirical studies.

The assumption that traders place limit orders at uniform distance away from the last trade price is an incorrect assumption in today's market. According to the data provide by the Commodity and Futures Trade Commission, high frequency traders, which make up $70 \%$ of the trades in the equity market and $35 \%$ of trades in the E-mini S\&P 500 (Staff SEC \& CFTC 2010 place $60 \%$ of all their orders 1 tick or closer to the last trade price. Additionally, cancelation of orders can be a large contribution to extreme market events (Kirilenko et al. 2011). Thus, without this key functionality, it calls into question the Maslov's (2000) model ability to accurately replicate modern markets as well as simulate extreme market phenomenon.

Samanidou, et al. in 2007 did a review of agent based model of financial markets. Financial agent based models can be categorized into 3 major categories. Models containing agents that are completely random, agents that switch between several strategies depending on historical out comes, and dynamically learning agents. Each of these types of agent based models have positive and negatives. However, models that incorporate agents that are completely random are the easiest to attribute causation. This is because random agent models do not confound results with assumed strategies or learning mechanism. Therefore, 


\section{Hayes, Paddrik, Todd, Yang, Beling, and Scherer}

the agent based model described in this paper uses agents that derive their actions from underlying distribution.

Using agent based modeling for policy decision is not a novel concept. In 2008, the European Union developed an agent based model design to test macroeconomic policies. This model incorporated several smaller models including credit, financial, and labor markets (Deissenberg 2008).

The financial aspect of the model was comprised of several kinds of agents, including households, firms, banks, a government agent and a central bank. Firms sell stocks to finance development of products, while the government agent issues bonds to finance debt. Household agents invest in theses assets in an attempt to make a profit. House hold agents and firms are provided with learning capabilities (Deissenberg 2008). This creates multiple contribution to the overall outcome of the market. It is not possible to determine if the learning capability or the interaction of agents is the cause of the market outcome. Additionally, it is possible that a altered learning algorithm will create different results. For this reason the agent based model in this paper was designed to be zero intelligent.

Frank Westerhoff (2008) studied the use of agent based modeling in several policy decisions. In his models agents can choose between a fundamental strategy and a technical strategy. Agents switch between strategies depending on which was more profitable. This creates a herding effect and generates the volatility clustering seen in real markets. Several rules were examined, most notably was trading halts. Trading halts pause trading when a price move is larger than a determined amount. He found that spikes and crashes were limited by trading halts. Additionally, he found that relative profits of agents remained unchanged by trading halts Although this model can characterize an order book it does not characterize the participants in the model.

It is the authors' assertion that to accurately represent modern markets, simulations must accurately represent market participants' behavior. Finding no such model in the ABM Financial Literature, a model was designed with the goal of representing agent classes, the hypothesis being that this type of model would provide a more realistic simulated market. This simulation could then be used to inform the regulation of financial markets.

\subsection{Rule Making Process}

When congress passes a law it is a policy statue, which federal agencies are required to implemented. Detailed regulations are developed through a process known as rulemaking. The rulemaking process for the CFTC is laid out in the Commodity Exchange Act (CEA) and the Federal Administrative Procedures Act (FAP) (United States Code $5 \& 7$ ).

The FAP requires a regulatory body follow formal steps before a rule can be implemented. The optional first step is to publish an advance notices on a proposed rule. In this notice, preliminary information on the subject area is presented. Additionally, public insight is requested to help shape the rule. After this initial step a proposed rule is published. The proposed rule is a draft, that contains the analysis and the justification for the rule.

The proposed rule is open to the public for comments. Written issues and concerns about the rule can be sent to the agency during this period. The CFTC must address every comment. However, comments can be grouped if they contain similar content. Thereby, relieving CFTC from having to address each individual comment separately. After the public comment period is closed the final rule is written and published. This rule lays out the new regulatory policy that will be implemented. Additionally this rule will address all public comments, as well as, contain the final analysis and justification for this rule.

The CEA requires the CFTC to complete additional steps in the rule making process. A notable step is to "Consider the Costs and Benefits" of any proposed regulation. Specifically the CFTC is required to complete the following task:

A) Consider how the regulation effects the protection of market participants and the public

B) Consider how the regulation effects efficiency, competitiveness, and financial integrity of futures markets

C) Consider how the regulation effects price discovery 
D) Consider how the regulation effects risk management practices

E) Consider how the regulation effects other public interest

It is important to note that the CFTC will consider the cost benefit analysis but is not required to alter the rule based on the findings. Additionally, the cost benefit analysis does not have to contain quantifiable costs and benefits.

Recently, private industries have sued on the grounds of inadequate cost benefit sections. December, 2011 the Securities Industry and Financial Markets Associations along with the International Swaps and Derivatives Association sued the CFTC over the Position limits rule (International swap 2011). Specifically, one claimed made is that the CFTC, "failed to give serious consideration to the significant costs that the position limits rule will impose on commodity markets and the broader economy." This is not the first law suit filed claiming a regulatory body's cost benefit analysis was insufficient. In July 2010, a Security and Exchange Rule was overturned citing inadequate cost benefit analysis (Holzer 2011).

Agent based modeling can help regulators examine the cost and benefits of proposed rules. By examining the affect the rule has on each agent, part $\mathrm{A}$ and $\mathrm{D}$ in the aforementioned list can be accomplished. Additionally, by looking at market measures as a whole part B, C, and E in the list of above can also be completed. The next section will detail how the agent based model was designed.

\section{FINACIAL AGENT BASED MODEL}

Current literature suggests that the markets are divided into subcategories of traders and the combinations of trading styles are responsible for emergent market events. These combinatorial aspects lead us to believe that it was necessary to have multiple categories of trading agents in the simulation. However, as to not presume specific trading strategies for agents, it was necessary to design the agents to be zero intelligent. The agents were design with constraints on their behaviors, such as position limits.

From (Kirilenko et al. 2011) and (Staff SEC \& CFTC 2010), we were able to use their characterizations of the participants of the E-Mini S\&P Futures market by placing them into one of six categories of trader types:

Fundamental buyers and sellers take long or short positions on the asset during the entire duration the markets exists and trade with a low frequency.

Market makers take the position of straddling both sides of the market by taking long and short positions on an asset. Intermediaries' trades are meant to give the market liquidity.

Opportunistic take a long or short positions on the asset during the duration of the market day like a fundamental trader. However, they implement trading strategies that make them resemble Intermediaries because they do not take a large position.

High Frequency take long or short positions on an asset for short periods and trading with high frequency near the best-ask and best-bid sides of the book. HFTs in the simulation use a simple momentum strategy. As the bid/ask queues becomes imbalanced HFTs will tend to trade in the same direction as the imbalance. In other words if there are more bids in the order book HFTs have a higher probability of placing a buy order. This strategy was found in the data provided by the CFTC. HFTs will allow themselves to take large positions for short periods of time but will try to be neutral by the end of day.

Small Traders - take either a long or short positions on the asset during the entire duration of the markets exist and trade with a very low frequency.

Using work done by (Kirilenko et al. 2011) as a framework market participation was captured from data. The participation rates displayed in table 1 were used to construct our agents. 
Table 1: Listing E-Mini S\&P 500 market participation rates.

\begin{tabular}{|c|c|c|c|c|}
\hline Trader Type & $\begin{array}{c}\# \text { of } \\
\text { Traders }\end{array}$ & $\begin{array}{c}\text { Arrival } \\
\text { Speed }\end{array}$ & $\begin{array}{c}\text { Position } \\
\text { Limits }\end{array}$ & $\begin{array}{c}\text { Market } \\
\text { Volume }\end{array}$ \\
\hline Small & 6880 & $2 \mathrm{hr}$ & $-30-30$ & $1 \%$ \\
\hline $\begin{array}{c}\text { Fundamental } \\
\text { Buyers }\end{array}$ & 1268 & $1 \mathrm{~min}$ & $-\infty-\infty$ & $9 \%$ \\
\hline $\begin{array}{c}\text { Fundamental } \\
\text { Sellers }\end{array}$ & 1276 & $1 \mathrm{~min}$ & $-\infty-\infty$ & $9 \%$ \\
\hline $\begin{array}{c}\text { Market Mak- } \\
\text { ers }\end{array}$ & 176 & $20 \mathrm{sec}$ & $\begin{array}{c}-120- \\
120\end{array}$ & $10 \%$ \\
\hline $\begin{array}{c}\text { Opportunistic } \\
\text { High Fre- } \\
\text { quency }\end{array}$ & 5808 & $2 \mathrm{~min}$ & $\begin{array}{c}-120- \\
120\end{array}$ & $33 \%$ \\
\hline fec & 0.35 & $\begin{array}{c}-3000- \\
3000\end{array}$ & $38 \%$ \\
\hline
\end{tabular}

Due to the large number of traders the simulation was scaled to $1 / 32$ of the actual market. Additionally, since the scaling would only allow for $1 / 2$ an HFT, the speed of HFTs were slowed. Approximately four simulated HFTs represent 1 real world HFT. The simulated HFT average order arrival speed was set at 2 seconds. Therefore, a HFT orders arrive approximately every 0.5 seconds.

The classification of traders was determined using the following two variables.

* Trade Speed - Average amount of time taken between order placements or cancelations.

* Position Limit - Number of contracts allowed to be held.

Using order book data from the E-Mini S\&P 500 contract provided by the CFTC and the classification process, we described empirically the style in which the agents placed orders into the order book. This was done by determining each trading class order size and order price distribution.

* Order Size- Distribution of order quantity size.

* Order Price Selection - Distribution describing the number of ticks a order's price was in reference to the last trade price. (Figure 1 shows example of market maker distribution)

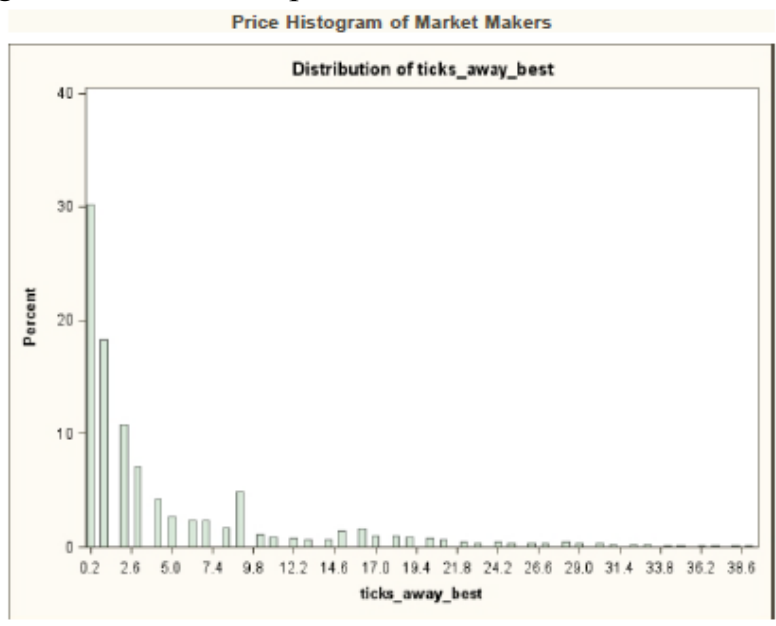

Figure 1: Market Maker distribution of order placement. 
Using these four variables in unison we were able to create the six classes of agent for our market. Agents act based on distributions associated with each class of traders. Figure 2 is a visual representation of an agent class.
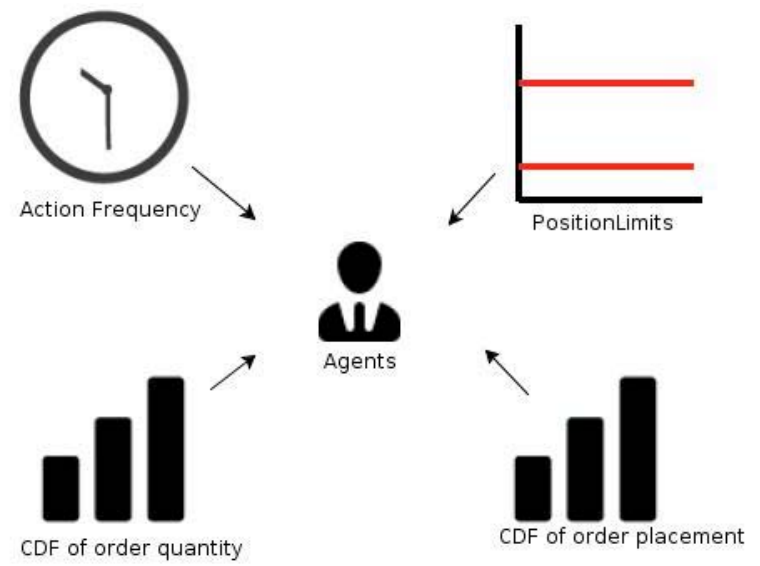

Figure 2: Components of an agent class.

The design of the simulated market exchange systems follows a traditional 'price then time' order book structure. This allows for asset price creation, to emerge from the market participants through their individual actions (order, cancel) and the market matching engine connecting them (execute). An in depth validation process of the agent based model is described in Agent Base Model of the E-Mini: For Flash Crash Analysis (Paddrik 2012).

\subsection{Experimental Procedures}

The SEC is contemplating a new rule (Security Exchange Commission 2010), which creates a minimum time before an order can be cancelled. For this experiment this rule will also include modification. To effectively cancel an order, traders can modify it away from the best bid or ask, until the minimum time expires. Therefore, a logical extension is to prevent a trader from modifying or canceling an order until a minimum time has expired.

It has been theorized that high frequency traders (HFT) cause the market to be more volatile and prone to large price movements (Zhang 2010). The minimum quote life rule seeks to decrease market volatility and large price movements. However, high frequency traders claim that this rule will force them to revalue their risk compensation and place orders farther from the best bid and ask. Which is theorized to cause spreads to rise, liquidity to decrease, and time to trade to increase. The goal of the experiment is to examine the impact of a minimum quote life rule on the E-Mini market.

The minimum time that an order must remain untouched was varied from 0-1.25 seconds. Over this time period, exogenous price shocks remain constant throughout every simulation. Additionally, empirical distributions that agents used to trade remained the same throughout this experiment. The underlying assumption is that all traders will trade in the same manner before and after the rule is implemented. This allows for the examination of the rule's impact, if the market is unchanged. This assumption will most likely be violated in the real world. However, since the strategies are unknown for each individual traders, it becomes impractical to estimate how order placement might change.

Market level variables are examined for the cost benefit analysis. The spread, distance between best bid and ask, is calculated and recorded for each minute. Additionally, liquidity ratio is determined for each minute. Liquidity ratio is a measure of how much a trade affects the current price. The formula is presented below (Dubofsky et al. 1984). 


$$
\text { Liquidity Ratio }=\frac{\sum \text { Volume } * \text { Price }}{\sum \mid \Delta \text { Price } \mid}
$$

The larger the liquidity ratio the less affect a single trade has on price movement. Liquidity Ratio was calculated for each minute. Additionally, several other measures of liquidity, market depth and time between trades, were studied. Lastly, the absolute value of minute price returns were calculated. This is used as a measure of volatility. Since each simulation experiences the same price herding shocks a larger price returns is indicative of higher volatility and not a fundamental difference in price between simulation runs.

\subsection{Results}

The minimum quote life rule is designed to dampen volatility (Security Exchange Commission 2010), which HFTs have been theorized to increase (Zhang 2010). For this reason, it is natural to first examine if volatility changes as the minimum quote life rule is made stricter. As illustrated in figure 3, over most of the parameter space volatility is shown to have an inverse linear relation with the minimum order life time. Additionally, the variance in the volatility calculated over the simulated month decreases as the minimum life time is increased. This indicates that HFTs do increase volatility in the market and implementing this rule will decrease it.

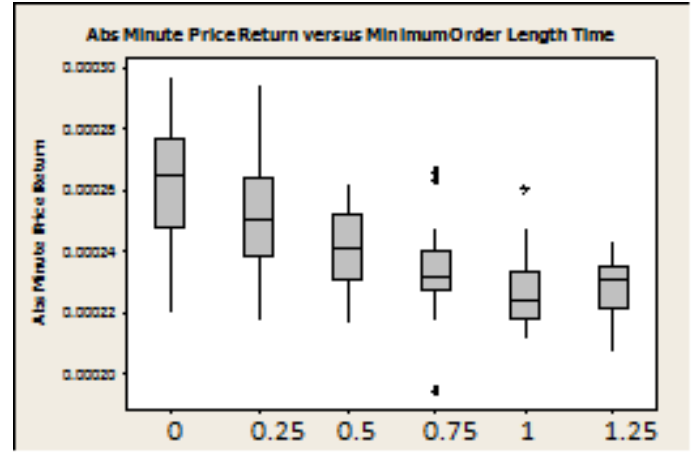

Figure 3: Determining absolute value of minute price returns.

The HFT participants claim they improve many market parameters such as liquidity (Brogaard 2010). Liquidity can be measured in many ways. However, in general terms it is the ability to buy or sell stocks and contracts quickly, without moving the price. HFT firms have stated an implementation of a minimum quote life rule would harm liquidity. To examine this claim several measures of liquidity were studied. Bid ask spread, the amount of money that must be paid if a trade is to executed immediately, is calculated every minute. Figure 4 illustrates the minimum quote rule lowers the bid ask spread. However, there is only marginal decrease as the minimum life time is increase from 0 second to 1.25 seconds. 


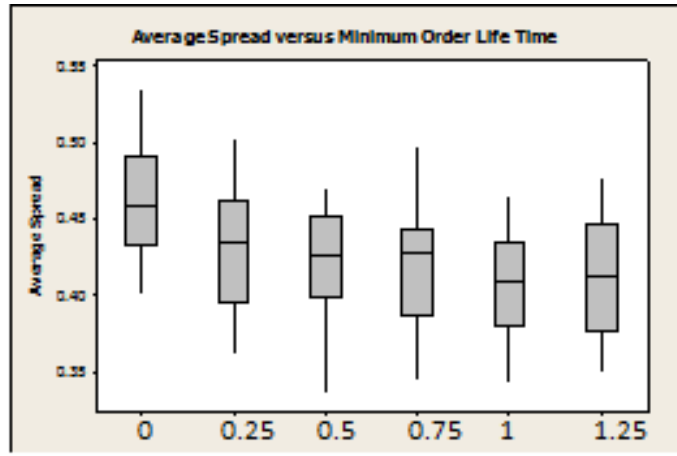

Figure 4: Investigating average daily spread.

Figure 4, shows a novel finding, which contradicts general consensus, that average daily spread will increase if such a rule was implemented. This will be discussed in greater detail in section 5 . It is important to note that the ticket size in the E-mini is $\$ 0.25$. Therefore, in almost every simulation the average spread was always between $1-2$ tickets. Another measure of liquidity is known as liquidity ratio. Liquidity Ratio indicates how many contracts or stocks can be traded without increasing the price. The higher the liquidity ratio, the more contracts or stocks can be traded without a significant price change. Figure 5, illustrates that the market seemingly has more liquidity after the rule is implemented.

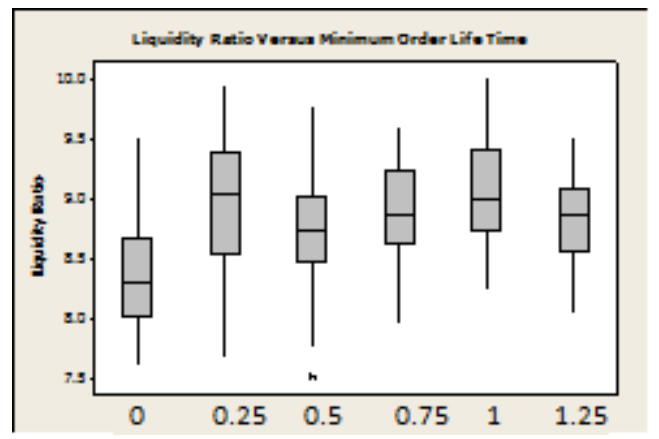

Figure 5: Studying liquidity ratio.

This is again contradictory to the prevailing consensus. As with bid ask spread, liquidity ratio improves once the minimum quote life rule is implemented. However, there is no statistically significant difference between a minimum life time of 0 second compared to 1.25 seconds.

An additional measure of liquidity is how long a resting order must wait before being traded against. HFTs cross the spread a significant amount, so it is believe that they lower this wait time. Figure 6 illustrates a minimum quote life rule increases time between trades. Furthermore, it has a linear relation over much of the parameter space, similar the absolute value of returns. 


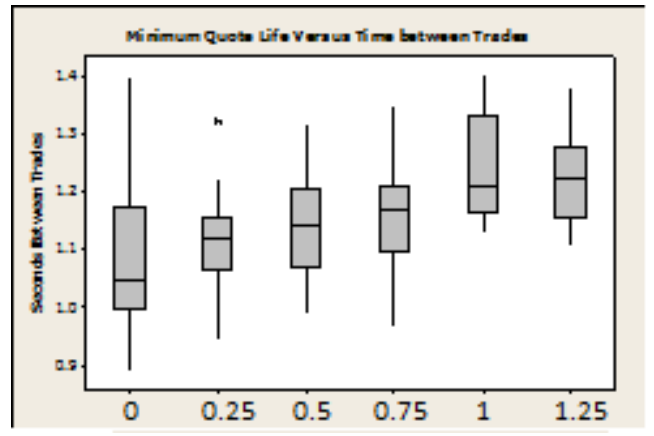

Figure 6: Examining time between trades.

The last measure of liquidity examined is market depth. The average daily market depth of the order book is presented in figure 7 . The larger the market depth the more orders are able to be executed without large price changes. The market depth increases after the minimum quote life rule is implemented, indicating a more liquid market after the rule is implemented. This would coincide with the previous finding that the time between trades increases after the rule is implemented, thus allowing for less overall trades and more resting orders. Although market depth appears highly variable there is no significant difference in means between 0 second and 1.25 second implementation of the minimum quote life rule.

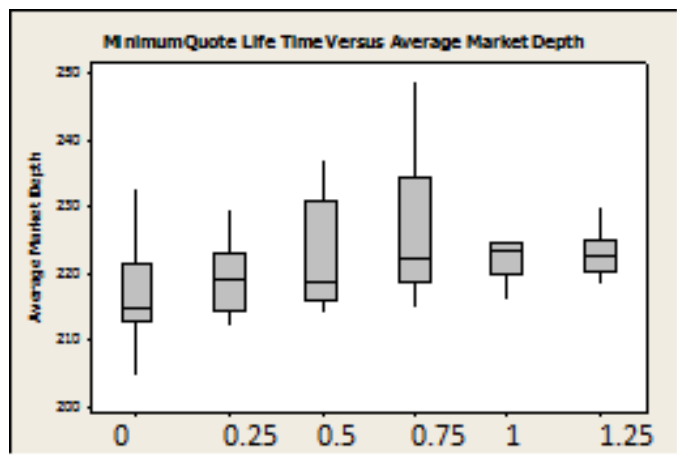

Figure 7: Determining market depth.

The next section will consolidate these findings into a cohesive cost benefit analysis of the rule. The goal is to show how the insight from this model can be used to facilitate discussion of new rules.

\section{COST BENEFIT ANALYSIS}

The simulation of the minimum quote life rule generated novel findings. Firstly, the rule only effects HFT trading strategies. HFTs are the only class of traders that routinely cancel or modify a new order within 1.25 seconds of placing it. Since this rule focus on traders with small time horizons, HFTs would be forced to develop new strategies costing them time and money. Although, they represent a small number of market participants they generate $35 \%$ of the trading volume in the E-Mini market and upwards of $70 \%$ in equity markets (Kirilenko et al. 2011). Therefore, any new strategy that is developed has the potential to cause even greater volatility then current strategies.

As the minimum quote life time is increased the absolute value of minute price returns decreased. We can attribute the decline in volatility to HFTs because they are the only class of trader directly affected by this rule change. HFTs aggressively cross the spread more frequently than other trading classes. In the model traders are only allowed one active order at a time, the minimum quote life rule acted as a throttle for HFTs. 
This throttle prevented HFTs from crossing the spread as frequently, thus decreasing the overall number of trades and increasing the time between trades. Since HFTs make up a large percentage of trades, as their speed is decreased the time between trades is increases. The aforementioned relationship between HFT speed and trading rate, the HFT strategy implemented in the simulation, and the herding mechanism explains why HFTs increase volatility.

As positive news enters the market through the herding mechanism, HFTs increase their probability of buying contracts. This adds pressure to prices and makes price tick up. As negative news enters the market the opposite occurs and prices falls. These price shocks occur at constant times for all simulation runs. The minimum quote rule limits HFTs ability to increase the price when positive news enters the market and decrease the price when negative news enters the market, by decreasing the amount they can trade in a given time period. This affectively dampens price movement, decreasing volatility. This can be seen in Figure 8.

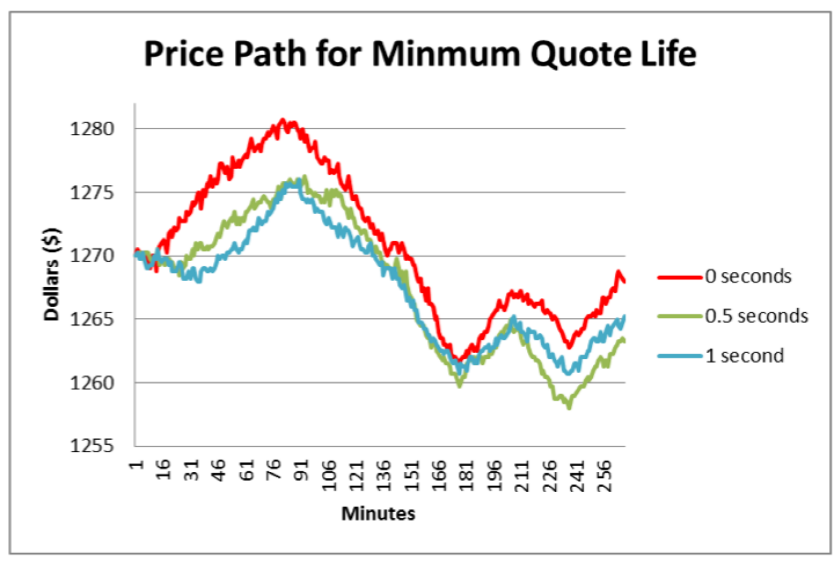

Figure 8: Measuring price paths through a day.

The graph was limited to three price paths for readability purposes. However, it illustrates that HFTs cause considerable impact on price movement. As their speed is limited by the minimum quote life rule, their ability to affect price is decreased and volatility consequently drops.

Market depth, liquidity ratio, and bid ask spread all have no significant change in values between a 0.25 second and a 1.25 second minimum life time implementations. This is because HFTs are not the only trading class that crosses the spread. Orders that executed immediately arrive from other trading classes at a random frequency and cause trades to occur. These trades lower market depth and occasionally will be large enough cause the bid ask spread to widen for a short period of time. In other words the aggregate effect of other trading classes not hindered by this rule create bounds on the overall market parameters. So although this rule may lower HFTs ability to take liquidity, the effects on variables, such as market depth, will be limited by other trading classes.

The analysis illustrates that the current debate over this rule has been framed in the wrong context. Currently, the debate focuses on bid ask spread versus volatility. Bid ask spread will be bounded by the aggregate trades of other classes, which have time horizons longer than seconds. The debate should focus on the tradeoff between order trade time and volatility. An example of a trading strategy that can be hurt by this rule is an ETF, which is tracking an index. If the ETF cannot acquire the necessary shares in a given timeframe then they must issue market orders and pay the bid ask spread. As the minimum life time is increased the probability that an ETF will have to issue a market order increases.

This rule will cause traders with time constraints to issue market orders more frequently. However, their market orders will be less likely to cause a price change. Thus, their market orders have a lower cost than if they are issued under the current rules. Depending where the parameters of the minimum quote life rule is set, it is possible to significantly decrease or increase the cost to traders with fixed time limits. Detail studies across different securities and commodity should be done to determine what the minimum 
quote time should be. There is no guarantee that the optimal quote life time will be the same for each security or commodity.

\section{CONCLUSION AND FUTURE WORK}

Using the agent based model regulators can derive a justification for why this rule should be implemented. Additionally regulators, can determine which traders will be directly affected by this rule. Lastly, the potential tradeoffs are illuminated through the simulation. Agent based modeling will not replace current fundamental techniques of economics. However, it can facilitate a decision makers understanding of the complex nature of the financial market. The model framework presented in this paper can be calibrated to any financial market. Thereby, making it a ubiquitous regulation tool.

This model makes several assumptions that limits its accuracy. First it assumes that traders only have one active order. Data supplied by the CFTC shows that HFTs generally have multiple orders on both size of the book. The current model does not examine how this rule will affect a multiple live order strategy. Additionally, the model assumes zero intelligence. This is because a trading strategy is difficult to recreate from order book data. For this reason it is impossible to use this model accurately determine how this rule will affect different trading classes profit and losses.

Future models will be expanded to incorporate real world trading strategies. These strategies will be derived from order book data through the use of machine learning techniques. This allows for more accurate modeling of real world participants. Moreover, it allows for the aforementioned assumptions to be relaxed.

\section{ACKNOWLEDGMENTS}

We would like to thank the members of the Commodity and Future Trade Commission, and Andrei Kirilenko, the Chief Economist of the Commodity and Future Trade Commission.

\section{REFERENCES}

Brogaard, J., 2010. "High Frequency Trading and its impact on Market Quality." http://www.nber.org/public_html/confer/2010/MMf10/Brogaard.pdf [Accessed April 16,2012]

Deissenberg, C., Sander. Hoog, H. Dawjd. 2008. "EURACE: A massively parallel agent-based model of the European economy." Applied Mathematics and Computation 204: 541-552.

Dubofsky, D. A. And J. C. Groth, 1984. "Exchange Listing and Stock Liquidity.” The journal of Finacial Research 7: $291-302$.

Dodd Frank Wall Street Reform and Consumer Protection Act http://www.sec.gov/about/laws/wallstreetreform-cpa.pdf [Accessed April 16, 2012]

Holzer, J. 2011 "Court Deals Blow to SEC, Activists" Wall Street http://online.wsj.com/article/SB10001424053111903554904576461932431478332.html [Accessed April 16, 2012]

International Swap and Derivatives Association, Case 1:11-cv-02146-RLW. In The United States District Court for the District of Columbia, Filed 12/02/11.

Kirilenko, A., A. S. Kyle, M. Samadi, T. Tuzun, 2011. "The flash crash: The impact of high frequency trading on an electronic market." http://dx.doi.org/10.2139/ssrn.1686004 [Accessed April 16, 2012]

Macal, C. And M. North, 2010 "Toward Teaching Agent-Based Simulation” In Proceeding of Winter Simulation Conference, Maryland, 2010.

Maslov, S. 2000. "Simple model of a limit order-driven market." Physica A: Statistical Mechanics and its Applications 278: $571-578$.

Paddrik, M., R. Hayes, A. Todd, S. Yang, W. Scherer, P. Beling, 2012. "An Agent Based Model of the E-Mini S\&P 500 and the Flash Crash.” In Proceedings of the 2012 IEEE Computational Intelligence for Financial Engineering \& Economics.

Security Exchange Commission, 2010. "Concept Release on Equity Market Structure” http://www.sec.gov/rules/concept/2010/34-61358.pdf [Accessed April 16, 2012]

Samanidou, E., E. Zschischang, D. Stauffer, T. Lux, 2007. "Agent-based Models of Financial Markets" Reports on Progress in Physics 70: 409450 .

The staff of the CFTC \& SEC, 2010. "Findings regarding the market events of May 6, 2010." http://www.sec.gov/news/studies/2010/marketevents-report.pdf [Accessed April 16, 2012].

United States Code Title 5 Chapter 2 “Federal Administrative Procedure Act” http://www.archives.gov/federal-register/laws/administrativeprocedure/ [Accessed April 16, 2012].

United States Code Title 7 Chapter 1. “Commodity Exchange Act.” http://www.cftc.gov/files/ogc/comex060601.pdf [Accessed April 16, 2012].

Westerhoff, F. 2008. "The use of agent-based financial market models to test the effectiveness of regulatory policies." Journal of Economics and Statistics 228: 195-227.

Zhang, F., 2010 “ High-Frequency Trading, Stocks Volatility, and Price Discovery.” http://dx.doi.org/10.2139/ssrn.1691679 [Accessed April 16, 2012] 
Hayes, Paddrik, Todd, Yang, Beling, and Scherer

\section{AUTHOR BIOGRAPHIES}

Roy Hayes is a doctoral student at the University of Virginia. He completed a Bachelors of Science in Aerospace and Systems Engineering at the University of Virginia in 2009. His research focuses on implementing machine learning techniques to Identify opponent strategies in game theoretical situations. Currently, Roy is applying Inverse Reinforcement Learning to uncover trading strategies in the commodity markets.

Mark Paddrik Mark Paddrik is a PhD Candidate with a MS \& BS in System Engineering and BA in Economics from the University of Virginia. He has done work in time series forecasting in US equities and futures for risk management for Pace Global Energy and ARC. A few papers that are related to this work include "strategies for hedging and trading in the emerging ethanol commodities market", "risk metric allocation methodology in financial markets", and "preventative market failure: a look at returns and information's effect on market liquidity". His current interests lay in the use of agent-based simulation for policy decision making in finance and health care. He works with the Commodities and Futures Trading Commission to help detect and prevent manipulative trading practices. With the UVA hospital he is helping to investigate how to prevent the creation and spread of drug-resistant bacteria.

Andrew Todd is a doctoral student in the Department of Systems and Information Engineering at the University of Virginia. He received a B.S. in Mathematics from the College of William and Mary in 2004. After working for Bank of America in technology for five years he left to pursue graduate work at the University of Virginia.

Steve Yang is a Ph.D. candidate at the Department of Systems and Information Technology at the University of Virginia. His research has focused on detecting financial information and trade based fraud in securities and derivatives markets. He received his M.E. in Engineering Management from the University of Virginia and M.S. in Computer Science Application from Virginia Tech. He is currently working as a Research Associate at the Chief Economist Office of the Commodity Futures Trading Commission in Washington DC. He has worked with both the SEC and CFTC on financial information standardization. In 2008, Mr. Yang was selected by the SEC and the FASB as one of the core team members to build the first U.S. GAAP XBRL Taxonomy in New York.

Peter Beling is an Assistant Professor in the Department of Systems Engineering at the University of Virginia. Dr. Beling joined the University of Virginia after receiving his Ph.D. in Industrial Engineering and Operations Research from the University of California at Berkeley. Dr. Beling is the founder of the Financial Engineering Research Group at the University of Virginia. He is an Associate Editor for International Abstracts in Operations Research and has served as a referee for numerous journals. He is Chair of the Technical Committee on Optimization and Search for IEEE Systems, Man, and Cybernetics society.

William Scherer has served on the faculty since 1986. He has authored and co-authored numerous publications on intelligent decision support systems, combinatorial optimization, and stochastic control. He is an associate editor for International Abstracts in Operations Research and reviewer for Operations Research, Annals of Operations Research, and IEEE Trans-actions on Intelligent Transportation Systems (ITS). He co-writes papers on case-based engineering education for the ASEE Journal on Engineering Education. He is vice-president of the IEEE Intelligent Transportation Systems Society. He has held the Lucien Carr III Professorship of Engineering, recognition of his excellence in undergraduate education. 